\title{
FORMAÇÃO DO PROFESSOR DE EDUCAÇÃO INFANTIL NO MUNICÍPIO DO RIO DE JANEIRO: CENARIO E DIALOGO COM OS SABERES.
}

Lidiane Castro Reto ${ }^{1}$

Resumo. A formação do professor é considerada como um dos fatores mais relevantes para promover os padrões de qualidade adequados na educação. A literatura de Nunes, Corsino e Kramer (2013) revela que nos municípios do estado do Rio de Janeiro, do período de 1999 a 2009, houve avanços na educação infantil, tais como: a expansão das matrículas nas creches públicas; organização e funcionamento das secretarias no que concerne à especificidade da educação e às equipes pedagógicas de acompanhamento da educação infantil. Entretanto, inúmeros aspectos precisam de atenção urgente das políticas públicas municipais, entre eles o aprimoramento através de formação continuada, formação em serviço e a construção da identidade do professor de educação infantil. Este texto tem por objetivo geral discutir a formação do professor de educação infantil e o seu desenvolvimento profissional no município do Rio de Janeiro e propõe como questões de estudo: Quais tem sido as possibilidades e experiências de formação que o professor de educação infantil tem encontrado na rede pública? Quais são as estratégias privilegiadas para a formação continuada dos professores de educação infantil? Até que ponto a formação tem propiciado a reflexão sobre a própria prática? Por meio de uma pesquisa qualitativa que se valeu de entrevistas e grupo focal realizada junto a professores e gestores de educação infantil pode-se investigar o cenário atual de formação e a percepção dos docentes. No que se refere a formação continuada oferecida no município do Rio de Janeiro pode-se afirmar que apesar dos esforços de envolvimento dos pais, gestores e professores no dia a dia da educação infantil, na efetivação das estratégias de formação prevalece os eventos pontuais como jornadas e seminários, em que não se garante o espaço de reflexão sobre a própria prática.

Palavras-chave: Formação de Professores; Educação Infantil; Desenvolvimento Profissional.

\section{EDUCATION TEACHER TRAINING CHILDREN IN RIO DE JANEIRO MUNICIPALITY: SCENARIO AND DIALOGUE WITH KNOWLEDGE}

Abstract. Teacher education is considered as one of the most relevant factors to promote the quality standards appropriate education. The Nunes literature, Corsino and Kramer (2013) reveals that in municipalities in the state of Rio de Janeiro, the 1999 to 2009 period, there were advances in early childhood education, such as the expansion of enrollment in public kindergartens; organization and functioning of the secretariats

\footnotetext{
${ }^{1}$ Universidade Estadual do Rio de Janeiro - Brasil - lidianecr@hotmail.com
} 
regarding the specificity of education and pedagogical teams monitoring of early childhood education. However, several aspects need urgent attention from local public policies, including improvement through continuing education, in-service training and the construction of the identity of the professor of early childhood education. This text has the objective to discuss the training of teachers of early childhood education and their professional development in the municipality of Rio de Janeiro and proposes to study questions: What has been the opportunities and experiences of training the teacher of early childhood education has found in public network? What strategies are privileged to the continued training of preschool teachers? To what extent the training has led to the reflection on the practice itself? Through a qualitative research made use of interviews and focus group conducted with teachers and early childhood education managers can investigate the current situation of training and the perception of teachers. As regards continuing education offered in the city of Rio de Janeiro can be said that despite the involvement efforts of parents, administrators and teachers on the day of child education, effective training strategies prevails the specific events such as conferences and seminars, where there is no guarantee the reflection on the practice itself..

Keywords: Teacher Training; Child education; Professional development.

\section{Introdução}

No Brasil, a educação infantil é direito de todos, sendo disponibilizada em creches (crianças de zero a três anos), e pré-escolas ou escolas (crianças de quatro a seis anos). De acordo com Nunes e Kramer (2013), existem diferenças nas condições de acesso e frequência, nos tipos de equipamentos existentes, na formação de docentes, tanto em creches e pré-escolas quanto em educação infantil e ensino fundamental.

Para exercer o trabalho docente em educação infantil, entende-se que são necessárias uma formação sólida, vivência e formação continuada ao longo da trajetória profissional. É recomendado que o professor se dedique constantemente ao processo de aperfeiçoamento e de reflexão crítica sobre suas próprias práticas pedagógicas, mantendo-se em sintonia com a realidade moderna e com as necessidades da criança, tanto em relação ao seu desenvolvimento quanto aos processos de aprendizagem.

A formação de professores e gestores que atuam na educação infantil e no ensino fundamental representa um processo longo e complexo. Para Salgueiro (2009), a valorização e melhor remuneração que o profissional docente deseja dependem, em grande parte, de formação e atuação profissional. Nunes e Kramer (2013) salientam que é necessário que se garanta 
conhecimentos científicos e acesso à produção cultural e à criação, num contexto de formação cultural.

Tardif (2014) observa que a atividade profissional de professor deve ser considerada como um espaço prático de produção, de transformação e de mobilidade de saberes, do saberfazer, específicos do ofício do professor, isto é, de dedicação.

Dentro do contexto apresentado, esta pesquisa teve como objetivo analisar a formação do professor de educação infantil e o seu desenvolvimento profissional no município do Rio de Janeiro refletindo sobre a formação do professor de educação infantil entre os saberes e as práticas. Apreendemos através de entrevista semiestruturada e do grupo focal quais tem sido as possibilidades e experiências de formação que o professor de educação infantil tem encontrado na rede pública, discutindo até que ponto a formação continuada oferecida pelo município do Rio de Janeiro tem contribuído para o fazer docente dos professores de educação infantil. Os avanços das políticas públicas no nosso país em relação à democratização do acesso à escola têm sido visíveis quando se considera o aumento do número de matrículas e a melhoria da qualidade dos sistemas de ensino municipais, estaduais e federais. Nunes, Corsino e Kramer (2013) realizaram um diagnóstico da gestão educacional em 92 municípios do estado do Rio de Janeiro, de 1999 a 2009, e foram comparados dados coletados nas secretarias municipais de educação, em relação à gestão e à formação dos profissionais, objetivando conhecer a educação infantil dos municípios do estado do Rio de Janeiro.

Aponta-se nesse estudo voltado para gestão e formação que houve avanços como a expansão das matrículas nas creches públicas, organização e funcionamento das secretarias no que concerne à especificidade da educação infantil e às equipes pedagógicas de acompanhamento da educação infantil. Constatou-se maior preocupação dos municípios com o envolvimento da equipe que trabalha diretamente com as crianças de zero a seis anos em projetos de formação, apontando investimento crescente com a qualificação desses profissionais (NUNES, CORSINO e KRAMER, 2013).

Com base nesse estudo longitudinal tem-se como questões norteadoras para a pesquisa no âmbito do município do Rio de Janeiro:

a) Quais têm sido as possibilidades e experiências de formação que o professor da rede publica da Educação Infantil? Quais são os programas de formação continuada oferecida aos professores de educação infantil da rede municipal do Rio de Janeiro?

b) Quais são as estratégias privilegiadas para a formação continuada dos professores de educação infantil? Até que ponto a formação tem propiciado a reflexão sobre a própria prática?

RPI Revista de Pesquisa Interdisciplinar, Cajazeiras, v. 2, n. 2, 157-171, jun/dez. de 2017. 
Discute-se a partir de alguns autores, como Gatti (2009), Imbernón (2009), Pimenta (2014), Kramer (2006) e Salgueiro (2009) as relações entre a formação de professores e o desenvolvimento profissional docente. O estudo contribui para as políticas educacionais de âmbito nacional e municipal voltadas para a formação do professor da educação infantil, analisando as características dos programas de formação continuada disponibilizada para os professores de educação infantil da rede municipal do Rio de Janeiro.

\section{Formação de professores e desenvolvimento profissional docente}

O conceito de formação de professor está associado à ideia de processo, trajetória de vida pessoal e profissional que envolve opções, vai de encontro à necessidade de construção de patamares cada vez mais avançados de ser, saber e fazer. É possível, também, relacionar a formação de professores com o desenvolvimento pessoal, em conjunto com o desenvolvimento profissional.

Segundo Gatti (2009) o desenvolvimento profissional configura-se com condições que vão além das competências técnicas, ou seja, configura-se como uma

"[...] integração de modos de agir e pensar, implicando num saber que inclui a mobilização de conhecimentos e métodos de trabalho, como também a mobilização de intenções, valores individuais e grupais, da cultura da escola [...]" (p. 98).

A profissão do professor requer uma produção e transmissão de conhecimentos contínuos. Diante das novas realidades e da complexidade de saberes envolvidos na sua formação profissional, é preciso assegurar uma formação consistente, ao mesmo tempo em que se mobiliza a capacidade operativa e os propósitos éticos de modo que o professor possa atuar em meio e com a diversidade cultural.

Para Arroyo (2007) a formação de professores tem sido muito discutida dentro de uma perspectiva transformadora. Trata-se de um movimento em que o processo de formação contínua ocupa lugar de destaque, em associação crescente à evolução qualitativa das práticas formativas e pedagógicas.

Em relação às práticas de formação de professores, a tendência investigativa preponderante parte da concepção do ensino como atividade reflexiva. Dentro dessa perspectiva, Libâneo (2006) define como um conceito que perpassa não somente a formação de professores como também o currículo, o ensino, a metodologia de docência. A ideia é a de que o 
docente possa pensar sua prática, ou seja, que ele desenvolva uma capacidade reflexiva sobre o seu próprio trabalho, a sua maneira de ensinar, de forma a delinear os seus objetivos e instrumentos de trabalho. Acredita-se que os professores possuem e reconstroem teorias que podem ajudar na construção de conhecimentos referente ao ensino.

Imbernón (2009) esclarece que nos dias de hoje, há programação e se oferece muita formação, mas existe pouca inovação ou, a inovação não é proporcional à formação que existe. Ele argumenta que talvez uma das razões seja que ainda predomina a formação de caráter transmissora, com a supremacia de uma teoria ministrada de modo descontextualizado, longe dos problemas práticos do professor e de seu contexto.

O autor ressalta que é preciso reavaliar os processos de formação que não ocasionem inovação, mas isso não é fácil. A solução não é somente associar a formação do professor e ao contexto sem desenvolver uma nova cultura formativa que crie novos processos na teoria e na prática da formação, inserindo o professor em novas perspectivas e metodologias.

Emerge nesse debate o conceito de profissionalidade docente postulado por OliveiraFormosinho (2002), que se refere à ação profissional integrada que a pessoa da professora desenvolve junto às crianças e famílias baseada em seus conhecimentos, competências e sentimentos, assumindo a dimensão moral da profissão. A autora entende que esses conhecimentos, sentimentos e competências englobam estágios complexos, distintos, evolutivos e interdependentes de interações, relações e integrações.

Kishimoto (2005) salienta que as pedagogias da educação infantil deveriam tratar de concepções a respeito de criança e educação infantil, suas práticas e formas de gestão e supervisão, que estejam direcionadas as crianças pequenas, de creches, ou as maiores, dos centros infantis. Essas concepções e práticas integradas permitem o entendimento da criança como ser ativo, portador de identidade e de cultura, que se diferenciam da abordagem de áreas disciplinares, que segmenta o conhecimento. De acordo com a autora, a formação do pedagogo em habilitação integrada por magistério de educação infantil e séries iniciais do ensino fundamental gera o viés da multiplicação de fundamentos e metodologias de ensino, em áreas disciplinares de matemática, ciências, português, história, geografia, educação física e artes, o que cria um modelo de curso que reproduz práticas de ensino fundamental. A pouca presença de conteúdos sobre o trabalho na creche demonstra a falta de especificidade da educação infantil, reitera a antecipação da escolaridade e o descuido com pressupostos de qualidade, como a integração entre o cuidado e a educação.

De acordo com Kramer (2006), a formação dos profissionais da educação infantil, professores e gestores, representam um desafio que demanda a ação conjunta das esferas municipais, estaduais e federal. Esse desafio possui muitas vertentes, necessidades e 
possibilidades, e atuação, tanto em relação à formação continuada - em serviço ou em exercício, como se tem chamado a formação daqueles que já trabalham como professores - quanto na formação inicial no ensino médio ou superior.

\section{Entre o conhecimento e a experiência, os saberes e as práticas na Educação Infantil.}

\section{Eixo do conhecimento - saberes teóricos}

Para Bodnar (2013), na maioria das propostas de formação continuada dos professores, a relação teoria e prática ainda é um desafio para os formadores, bem como para as instituições formadoras. Os profissionais da educação, os pesquisadores e a literatura da área da formação vêm apontando a necessidade de serem elaboradas propostas de formação que permitem a problematização das práticas pedagógicas dos professores, para que eles possam transformar ou potencializar as suas ações.

Bodnar (2013) comenta que a precariedade da formação dos professores da educação infantil é um assunto antigo, associado à própria indefinição de papéis do profissional que trabalha com crianças pequenas. De acordo com Kishimoto (2011, p. 107):

Desde tempos passados, acumulam-se os problemas na formação em decorrência da pouca clareza do perfil profissional desejado nos cursos de formação propostos. As contradições aparecem nos cursos amorfos, que não respeitam a especificidade da educação infantil.

Os documentos oficiais que indicam as diretrizes para a formação de professores, por sua vez, segundo Bodnar (2013), não ajudam muito para explicar qual seria o perfil desejado para esse profissional. A autora faz referência à dissertação de mestrado de Bonetti (2004), em que é discutida a especificidade da docência na educação infantil com base na análise dos documentos que tratam da formação inicial de professores para a educação básica elaborados após a LDB nº 9.394/96. O currículo e o ensino de conteúdos são concebidos como foco central do trabalho do docente e Bonetti ( 2004) constata que as orientações relacionadas aos docentes da educação infantil se encontram diluídas nos instrumentos legais analisados, sendo necessária uma vasta "garimpagem" para identificá-las.

Em relação ao magistério, a formação é oferecida por distintas entidades em diferentes níveis: nas universidades (pedagogia e licenciatura); no curso normal superior dos institutos superiores de educação; e no antigo normal em nível médio o que constitui, então, uma das dificuldades a ser encarada para se entender a profissão de magistério. Ainda há pouco acesso a cursos de formação específica, como cursos de atualização e pós-graduação que contemplem à

RPI Revista de Pesquisa Interdisciplinar, Cajazeiras, v. 2, n. 2, 157-171, jun/dez. de 2017. 
criança de creche e de pré-escola e a formação dos profissionais que trabalham nestes segmentos.

Mello (2000) apud Salgueiro (2009) ainda revela que a prática deverá estar presente no curso de formação docente, possibilitando a construção de competências a partir de experiências vividas no dia a dia (estágio em escolas equivalente à residência médica).

Os desafios da formação dos professores de educação infantil são muitos e estão envoltos numa política educacional para a infância que, mesmo com alguns avanços, não conseguem ampliar nem a oferta de vagas para as crianças e nem disponibilizar espaços de formação inicial e continuada que deem conta de atender à demanda por profissionais qualificados.

\section{Eixo da prática/experiência - saberes da prática}

Tardif (2014) parte do princípio de que os professores são atores competentes, indivíduos ativos, e deve considerar que a prática dos mesmos não é somente um espaço de aplicação de saberes oriundos da teoria, mas também um espaço de produção de saberes específicos provenientes dessa mesma prática. $\mathrm{O}$ trabalho dos professores de profissão deve ser considerado como um espaço prático específico de produção, de transformação e de mobilização de saberes e, nesse sentido, de teorias, de conhecimentos e de saber-fazer específicos ao ofício de professor.

Considerando essa perspectiva, isso significa a fazer do professor, tal como o professor universitário ou o pesquisador da educação, uma pessoa do conhecimento, um ator que desenvolve e detém sempre teorias, conhecimentos e saberes de sua própria ação. Tardif (2014, p. 11) esclarece que:

O saber dos professores é o saber deles e está relacionado com as pessoas e a identidade deles, com a sua experiência de vida e com a sua história profissional, com as suas relações com os alunos em sala de aula e com os outros atores escolares na escola, etc. Por isso, é necessário estudá-los, relacionando-os com esses elementos constitutivos do trabalho docente.

Ao afirmar que os professores são atores competentes e sujeitos do conhecimento, Tardif posiciona a subjetividade no centro das pesquisas sobre o ensino e sobre a formação de modo geral. Dessa forma, não é possível separar a prática profissional da subjetividade do professor, porque existe um imbricamento entre o conhecimento pessoal e profissional.

A vida do professor, dentro e fora da escola, segundo Oliveira (2013), tem um impacto significativo sobre sua prática profissional. Assim, é essencial a relevância de a formação estar 
associada a realidades vivenciadas pelo professor, porque o contexto profissional e a experiência pessoal estão interligados.

Nesse contexto, os professores deixam de ser vistos como técnicos que empregam conhecimentos criados por outras pessoas e passam a serem considerados como sujeitos que assumem sua prática a partir dos significados que eles próprios constroem, possuindo conhecimento e um saber-fazer oriundo de sua própria atividade.

A mudança na formação dos profissionais pode dar a conotação de uma "nova" profissionalidade aos docentes pela renovação da cultura profissional e organizacional da escola. A produção de materiais pedagógicos e a disponibilização de experiências significativas vivenciadas e desenvolvidas no dia a dia das escolas por professores em serviço são importantes na formação inicial daqueles que buscam, nos cursos de formação, uma qualificação que atenda melhor às exigências do nosso mundo, capaz de ressignificar o sentido de ser professor na contemporaneidade (OLIVEIRA, 2013).

Fica evidente que a teoria e a prática são portadoras e produtoras de práticas e de saberes, de teorias e de ações, e ambas influenciam o professor, seus conhecimentos e suas subjetividades. Entretanto, ressignificar os saberes docentes não quer dizer apenas aproximar teorias e práticas, mas articulá-las, fazê-las conversar, de maneira a fundamentar habilidades e competências, o saber-fazer e o saber-ser do professor como indivíduo e profissional.

Dessa forma, segundo Oliveira (2013) é preciso criar maior articulação entre os professores atuantes no espaço de formação da Universidade e as professoras atuantes nas escolas da educação básica, cujas práticas também são produtoras de saberes.

Pimenta (2014) explica que a atividade docente é práxis, e como tal, engloba o conhecimento do objeto, a criação de finalidades e a intervenção no objeto para que a realidade seja transformada, enquanto prática social. Teoria e prática são indissociáveis. É necessário instituir na escola uma cultura de análise de suas práticas.

Ainda, de acordo com Pimenta (2014), os saberes da experiência são também aqueles em que os professores produzem no seu dia a dia docente, num processo contínuo de reflexão a respeito da sua prática, mediatizada pela de outrem - seus colegas de trabalho, os textos elaborados por outros educadores. É nesse instante que ganham relevância na formação de professores os processos de reflexão sobre a própria prática e do desenvolvimento das habilidades de pesquisa da prática.

Lopes (2005) enfatiza que o professor/educador precisa falar de sua prática, de seus temores, de seus sonhos, de suas inseguranças, de suas certezas, de seus sentimentos de afeto e de raiva, de sua impotência. Para isso, é importante que ele seja ouvido, que tenha um 
profissional com quem discutir de modo contínuo sua prática, que o auxilie a enxergar caminhos, saídas e teorias.

Para Salgueiro (2009), independente da formação de cada um dos profissionais da equipe, é necessário que a prática diária seja continuamente avaliada (refletida), por meio de observações diárias, trocas entre profissionais, reuniões, discussão e revisão do planejamento pedagógico, discussão de casos, entre outros, como maneira de manter o profissional atualizado, não como um simples complemento de uma formação inicial deficitária, mas propiciando efetiva formação continuada.

Cenário da Formação da Educação Infantil do Município do Rio de Janeiro: propostas e organização.

A nova legislação educacional e as reformas que vêm sendo introduzidas nos sistemas educacionais estaduais e municipais nos últimos anos trouxeram consigo uma nova perspectiva para a abordagem da formação e da carreira dos professores, que abre possibilidades muito interessantes. Talvez pela primeira vez no país, começa a se pensar um perfil de educador adequado às características e necessidades de alunos em diferentes fases de seu desenvolvimento.

No Município do Rio de Janeiro existem duas modalidades de atendimento da Educação Infantil, a creche e a pré-escola. A educação infantil é uma etapa da educação Básica que se divide em duas modalidades. A creche que é o atendimento as crianças de zero a três anos e onze meses e pré-escola que é o atendimento as crianças de quatro a cinco anos e onze meses. Historicamente essas modalidades são marcadas e diferenciadas na rede municipal. A pré-escola, já antiga, consolidada, com um trabalho que já vem sendo desenvolvido ao longo de muitos anos, coberta pela legislação desde os anos 70 e 80 e praticamente universalizada na rede municipal de ensino. Mas com uma característica, a maioria desse segmento funciona e localiza-se em escolas de Ensino Fundamental, ocupando, por vezes, uma pequena área da escola. Os professores que atendem prioritariamente esse segmento são classificados como professores II que entravam na rede e podiam atender desde a Educação Infantil (pré-escola) até o Ensino Fundamental.

A creche que era vinculada a Saúde e a Assistência Social tem sua entrada oficial para a Educação no município do Rio de Janeiro em 2001, e passa a ser responsabilidade do município oferecer essa modalidade. Além das creches e escolas

RPI Revista de Pesquisa Interdisciplinar, Cajazeiras, v. 2, n. 2, 157-171, jun/dez. de 2017. 
existem no município os Espaços de Desenvolvimento Infantil (EDI) que comportam as mesmas crianças, porém com estruturas físicas diferentes. Nesses espaços é possível atender a Educação Infantil toda em um único lugar. Alguns EDIs atendem as duas modalidades no prédio e alguns não. Uns priorizam o atendimento da creche (de zero a três anos) e outros priorizam o atendimento a pré-escola (de quatro a cinco anos). Existem 449 unidades de Educação Infantil no Município do Rio de Janeiro divididas em 247 Creches Públicas e 206 Espaços de Desenvolvimento Infantil (EDIs), e 163 Creches conveniadas. Possuem 69.911 alunos em creches e 82.239 alunos na pré-escola. Atualmente, a rede possui 3.979 professores de Educação Infantil.

Com a expansão de vagas, percebeu-se uma necessidade maior de formar esse professor que atua especificamente na creche. O primeiro profissional concursado para trabalhar na creche foi o Agente Auxiliar de Creche. Nesse primeiro movimento, em 2007, havia uma preocupação maior em constituir esse profissional para a questão dos cuidados de saúde embora ele tivesse toda uma atuação pedagógica. Em 2011 foi criado o cargo de Professor de Educação Infantil (PEI) no Município do Rio de Janeiro e foi realizado seu primeiro concurso público.

De acordo com os dados da entrevista com a equipe de Gerência de Educação Infantil do Município do Rio de Janeiro encontramos três grandes formações destinadas a formação do professor de Educação Infantil, são: a Jornada Pedagógica, a Semana de Educação Infantil e o Seminário de Desenvolvimento infantil .

A Jornada Pedagógica está em sua sétima edição em 2016 e se constitui em um espaço de formação que já faz parte do calendário anual da Educação Infantil. Os responsáveis das crianças matriculadas na rede são convidados a participar dos encontros, tendo como objetivo mostrar todo processo pelo qual passam nossos profissionais para adquirirem conhecimentos pertinentes a sua prática cotidiana. Dessa forma se busca enriquecer os debates e fortaleçer os laços entre os educadores e as famílias. A jornada é uma modalidade de formação que representa um momento rico de discussão e troca entre os profissionais envolvidos com a Educação Infantil e as famílias. São trazidos para dentro do grupo as principais discussões a cerca da educação infantil. A Gerência de Educação Infantil com parceria com a Multi Rio organiza toda a Jornada, definem os temas que serão abordados de acordo com a necessidade da rede, recolhidos em visitas aos espaços escolares. Convidam palestrantes, pesquisadores e professores para participarem de uma roda de conversa, que é gravada para posteriormente ser passada para a rede. Nos encontros existem dinâmicas das temáticas, filmes, músicas, rodas de conversa, entre outras atividades que permeiam a Jornada Pedagógica.

RPI Revista de Pesquisa Interdisciplinar, Cajazeiras, v. 2, n. 2, 157-171, jun/dez. de 2017. 
Abordam temas como: rotina, planejamento, o brincar, o desenvolvimento infantil, a afetividade, aspectos do desenvolvimento infantil que atravessam o fazer pedagógico. Os responsáveis das crianças são convidados para participar dos encontros,sendo que ainda se considera com uma frequência baixa.

A Semana de Educação Infantil e um evento que ocorre anualmente em agosto em que os responsáveis são convidados a participar da vida escolar de seu(ua) filho(a), com atividades inseridas no cotidiano das crianças. Esses encontros buscam unir a comunidade escolar, rever práticas, mostrar ao responsável o trabalho que é realizado neste espaço e valorizar a Educação Infantil. O evento culmina com um evento que tem sido realizado nas ultima edições no Parque de Madureira onde os pais participam das exposições, teatro, música, histórias e apresentações das crianças. O Seminário de Desenvolvimento Infantil proporciona encontros para a direção das unidades escolares de Educação Infantil. Tem o objetivo de tirar o diretor do foco administrativo e estimular seu olhar para entender essa criança. Acredita-se que com essa prática o gestor irá multiplicar esse conhecimento, levando para seu grupo. Ele ocorre uma vez ao ano, geralmente no final do segundo semestre.

\section{Relatos dos professores de Educação Infantil acerca dos momentos de formação oferecidos pelo município do Rio de Janeiro}
_ "O que mais me preparou foi em sala de aula".
_ "Vivendo com as crianças que construímos nossa prática diária".
_ "Falta aprendermos as especificidades desta faixa etária em nossa formação"

(Grupo Focal com Professoras de Educação Infantil. Rio de Janeiro. Moderadora: Lidiane de Castro Reto. 29/10/14)

Tais afirmativas foram extraídas do grupo focal realizada com sete professores da educação infantil de diferentes escolas da rede publica municipal, mantendo o caráter voluntário e homogêneo de participação. Pelas afirmativas é possível perceber as que a formação do educador infantil ocorreu mediante os desafios e angustias no dia a dia na sala de aula. Há uma lacuna quanto ao conhecimento específico sobre como atuar com a faixa etária. A ausência de conteúdos sobre o trabalho desenvolvido com crianças de zero a seis anos evidencia a falta de especificidade da educação infantil já apontado por KISHIMOTO (2005). Esses educadores 
chegam para trabalhar com seus alunos de zero a seis anos sem uma formação adequada. Alguns aprendem entre acertos e erros em sua prática diária, outros procuram cursos e especializações para aprimorar sua prática. Nesse sentido percebe-se a importância da formação inicial e continuada.

Sobre a formação continuada denominada Jornada Pedagógica que ocorre uma vez ao ano, os professores se referem dessa forma:

- "Eu as avalio como boas, pois são uma troca de experiências. Acredito que poderiam inovar mais nos temas abordados".

_ "Elas são insuficientes, pois ocorrem uma vez ao ano. Acho que os profissionais que participam dessa jornada, que promovem isso, eles não tem a prática. Foge da realidade da creche que atuamos".

_ "Quanto a formação específica para a Educação Infantil acredito que a prefeitura deveria elaborar cursos pautados nos Parâmetros Curriculares Nacionais da Educação Infantil. Trabalhar tudo que esta ali, o brincar, o cantar, o dançar,... o currículo da Educação Infantil”.

_ "São experiências que acrescentam, mas não da forma que deveriam, porque há falhas. Acho o material que foi elaborado pelo município muito bom, mas há falha quando não existe mediador que nos ajude por em prática de uma forma efetiva, então eu acho falho nesse sentido".

_ "Acredito que esses encontros e experiências são formadoras e proveitosas, mas acredito que elas podem melhorar. Chegando mais perto do nosso universo infantil, das nossas dificuldades. Mas tudo que existe nesse sentido na prefeitura, nos ajuda a refletir sobre nosso trabalho e são momentos de trocas, surgindo assim crescimento. Consigo tirar sempre algo de bom que vai me ajudar em sala de aula".

(Grupo Focal com Professoras de Educação Infantil. Rio de Janeiro. Moderadora: Lidiane de Castro Reto. 29/10/14)

Apesar de serem consideradas como bons momentos de troca de experiências e crescimento profissional, os professores observam como pontos frágeis: a pouca inovação, a distância dos problemas práticos do professor, o foco em debates teóricos de forma a descontextualizada, em que falta a reflexão sobre a própria prática.

RPI Revista de Pesquisa Interdisciplinar, Cajazeiras, v. 2, n. 2, 157-171, jun/dez. de 2017. 
E no espaço da escola? O que ocorre?

_ "Infelizmente a formação que ocorre na minha unidade não acontece de forma adequada. A gestão não facilita esses encontros, temos falta de profissional o que atrapalha o horário do planejamento em grupo. Antes tínhamos os Centros de Estudos que ocorriam toda última sextafeira do mês. Esses encontros foram reduzidos".

_ "Na escola não existe uma formação, na realidade, o que acontece é que a gente quase não se encontra, não tem troca de experiências, não tem troca de informações, não discutimos o trabalho desenvolvido. Pela falta de tempo, pelo trabalho mesmo na sala de aula, não conseguimos ter uma formação dentro da escola".

(Grupo Focal com Professoras de Educação Infantil. Rio de Janeiro. Moderadora: Lidiane de Castro Reto. 29/10/14)

Para Salgueiro (2009) é necessário que a prática diária seja continuamente refletida, por meio de observações diárias, trocas entre profissionais, discussão de casos, entre outros, como maneira de manter o profissional atualizado, não como um simples complemento de uma formação inicial deficitária, mas propiciando efetiva formação continuada.

\section{Considerações: Um longo caminho a percorrer...}

Este estudo buscou discutir a formação do professor de educação infantil e o seu desenvolvimento profissional no município do Rio de Janeiro. O professor de Educação Infantil da rede municipal do Rio de Janeiro encontra alguns espaços e possibilidades de formação, entre eles a Jornada Pedagógica que ocorre uma vez ao ano. As estratégias adotadas para a formação são prevalentemente jornadas e seminários anuais. Apesar de serem consideradas como bons momentos de troca de experiências e crescimento profissional, ainda existem lacunas como espaços para a reflexão.

Percebe-se também a falta de espaço para a reflexão ocorre no dia a dia do professor, na unidade que leciona. Segundo Pimenta (2014) os saberes da experiência são também aqueles em que os professores produzem no seu dia a dia docente, num processo contínuo de reflexão a respeito da sua prática, mediatizada pela de outrem - seus colegas de trabalho. Os encontros para Centros de Estudos são poucos no calendário escolar e nem sempre ocorrem por conta da organização da rotina de Educação Infantil.

RPI Revista de Pesquisa Interdisciplinar, Cajazeiras, v. 2, n. 2, 157-171, jun/dez. de 2017. 
É necessário que se abra espaço no ambiente da Educação Infantil para que o professor/educador fale de sua prática, de seus temores, de seus sonhos, de suas inseguranças, de suas certezas, de seus sentimentos de afeto e de raiva, de sua impotência, com a interlocução entre pares e a busca de apoio teórico. Para isso, é importante que ele seja ouvido, que tenha um profissional com quem discutir de modo contínuo sua prática, que o auxilie a enxergar caminhos, saídas e teorias. (LOPES, 2005). Como afirma Imbernón (2009) ressignificar os saberes docentes não quer dizer apenas aproximar teorias e práticas, mas articulá-las, fazê-las conversar, de maneira a fundamentar habilidades e competências, o saber-fazer e o saber-ser do professor como indivíduo e profissional.

Conclui-se que uma formação que atenda as especificidades da Educação Infantil é ainda um desafio. Percebe-se que existem lacunas a serem superadas nesse caminho e, embora, a rede de ensino da cidade do rio de Janeiro tenha construído algumas alternativas de debate e participação nas propostas de formação para docentes, gestores e pais, ainda há muito a fazer. Prevalece o trabalho docente, por vezes, isolado em que a construção coletiva e a forma interativa de reflexão são raros. Embora se reconheça que a formação continuada não seja o único fator responsável pela melhoria da qualidade da educação infantil, é preciso considerá-la preponderante para o desenvolvimento profissional do professor.

\section{Referências}

ARROYO, M. Ofício de mestre - imagens e auto-imagens. 9. ed. Petrópolis, Rio de Janeiro: Vozes, 2007.

BODNAR, Rejane. Relação teoria-prática na formação em serviço de profissionais da educação infantil: ressignificando a prática pedagógica. In: ROCHA, Eloisa; KRAMER, Sonia (orgs.).

Educação infantil - enfoques em diálogo. 3. ed. Campinas, São Paulo: Papirus, 2013.

BONETTI, Nilva. A especificidade da docência na Educação Infantil no âmbito de documentos oficiais após a LDB 9394/96. Dissertação (Mestrado) - Universidade Federal de Santa Catarina, Florianólis, 2004. Disponível em: <https://repositorio.ufsc.br/bitstream/handle/123456789/87889/203725.pdf?sequence=1> Acesso em: 26 de julho de 2015.

GATTI, B. Formação de professores: condições e problemas atuais. Revista Brasileira de Formação de Professores, v. 1, n. 1, p. 90-102, Maio/2009.

IMBERNÓN, F. Formação permanente do professorado: novas tendências. São Paulo: Cortez, 2009

KISHIMOTO, Tizuko. Pedagogia e a formação de professores(as) de educação infantil. ProPosições, v. 16, n. 3, p. 181-192, set.-dez. 2005. 
Encontros e desencontros na formação dos profissionais de educação infantil. In:

MACHADO, Maria. (org.). Encontros e desencontros em educação infantil. 4. ed. São Paulo: Cortez, 2011.

KRAMER, S. As crianças de 0 a 6 anos nas políticas educacionais no Brasil: educação infantil e/é fundamental. Educ. Soc., Campinas, v. 27, n. 96, Especial, p. 797-818, out. 2006.

LIBÂNEO, J. Adeus professor, adeus professora? Novas exigências educacionais e profissão docente. 9. ed. São Paulo: Cortez, 2006.

LOPES, M. Descompasso: da formação à prática. In: KRAMER, S. et al. Infância e educação infantil. 3. ed. Campinas, São Paulo: Papirus, 2005.

NUNES, M.; CORSINO, P.; KRAMER, S. Educação infantil e políticas municipais: um estudo longitudinal. Cadernos de Pesquisa, v. 43, n. 148, p. 152-175, jan.-abr. 2013.

NUNES, M.; KRAMER, S. Educação infantil e expansão da escolaridade obrigatória: questões para a política, a formação e a pesquisa. In: KRAMER, S.; NUNES, M.; CARVALHO, M.

(orgs.). Educação infantil: formação e responsabilidade. Campinas, São Paulo: Papirus, 2013.

OLIVEIRA, Julvan. Trajetos de formação e de atuação docente. In: CALDERANO, Maria; MARQUES, Gláucia; MARTINS, Elita (orgs.). Formação continuada e pesquisa colaborativa - tecendo relações entre universidade e escola. Juiz de Fora, Minas Gerais: UFJF, 2013.

OLIVEIRA-FORMOSINHO, J. O desenvolvimento profissional das educadoras de infância: entre os saberes e os afetos, entre a sala e o mundo. In: OLIVEIRA-FORMOSINHO, J.; KISHIMOTO, T. (orgs). Formação em contexto: uma estratégia de integração. São Paulo: Pioneira Thomson Learning, 2002.

PIMENTA, Selma. Formação de professores: identidade e saberes da docência. In: PIMENTA, Selma (org.). Saberes pedagógicos e atividade docente. 8. ed. São Paulo: Cortez, 2014.

SALGUEIRO, Maria. Amor e dedicação na formação do professor de educação infantil. In: BERNARDINI, Cristina (org.). Docência: desafios teóricos e práticos da profissão. Rio de Janeiro: 7Letras, 2009.

TARDIF, Maurice. Saberes docentes e formação profissional. 17. ed. Petrópolis, Rio de Janeiro: Vozes, 2014

RPI Revista de Pesquisa Interdisciplinar, Cajazeiras, v. 2, n. 2, 157-171, jun/dez. de 2017. 